\title{
Modelling and Simulation of Frequency Response on Input shaft/carrier of a Planetary Gear Train under the Influence of Vibration
}

\author{
1"ETUK, EM; ${ }^{1}$ EBHOJIAYE, RS; ${ }^{2}$ EKANEM, KR
}

\author{
${ }^{I}$ Department of Production Engineering, University of Benin, PMB 1154 \\ ${ }^{2}$ Department of Physics, Akwa Ibom State Polytechnic, Ikot Osurua, PMB 1200 \\ *Corresponding Author Email: alwaysetuk@gmail.com, other Emails: raphael.ebhojiaye@uniben.edu, ekanemkufre03@gmail.com
}

\begin{abstract}
The transmission of motion from one gear to the other in a planetary gear train usually result in unwanted conditions such as vibration due to poor gear assembly, high contact forces, high rotation speeds etc. The vibrating effect of the gear can result in higher or lower frequency response which may damage the gear or offer safe working condition. Using SOLIDWORKS 2018 version for the modelling, SimulationXpress was used to conduct frequency analysis on input shaft/carrier of a planetary gear train to understand its behaviour at different mode shapes during vibration. Results obtain from the input shaft/carrier frequency analysis showed natural frequency values of $1922.4 \mathrm{~Hz}, 1922.8 \mathrm{~Hz}, 2101 \mathrm{~Hz}, 2183.1 \mathrm{~Hz}$ and $2185.3 \mathrm{~Hz}$ for mode shape $1-5$. Geometry of the input shaft/carrier appeared differently at each mode number, resulting in frequency responses characterised by different modal shapes. This also led to gradual increase in the natural frequency of the input shaft/carrier at increasing mode no, consequently causing deflection on the mode shapes of the input shaft/carrier model. Hence, vibration should be reduced to the lowest limit of tolerance for minimum deflections and longevity of the input shaft/carrier and planetary gear components.
\end{abstract}

\section{DOI: https://dx.doi.org/10.4314/jasem.v25i4.16}

Copyright: Copyright ( 1021 Etuk et al. This is an open access article distributed under the Creative Commons Attribution License (CCL), which permits unrestricted use, distribution, and reproduction in any medium, provided the original work is properly cited.

Dates: Received: 14 February 2021; Revised: 26 March 2021; Accepted: 12 April 2021

Keywords: Modeling, Vibration, Planetary gear, Input shaft, Frequency, Mode shapes, Carrier.

Planetary gears also known as epicyclic gears are widely used for the transmission of power in various fields of application such as aerospace, wind turbines, automotive, marine etc. They offer a number benefits including high efficiency, compactness, high torque to weight ratio, multiple gear ratios and minimal noise compared to fixed-shaft gearboxes (Moshrefzadeh and Fasana, 2017). However, the input and output shafts of epicyclic trains are concentric so no bending moments or torques are created from radial forces that develop from the change of the force's line of action. It consists of a sun gear, planetary gears, internal gear and a carrier, of which the internal gear is fixed, the sun gear is the input pinion, and the output shaft is part of the carrier. Investigations carried out on planetary gear train and its operating members have contributed immensely to its in-service operation. For example, the application of instantaneous shaft speed measurement by instantaneous frequency estimation of the vibration signal was studied by Zimroz et al. (2011). It was proposed that using advanced signal processing techniques for instantaneous shaft speed recovery from a vibration signal is more ideal than using extra channels or in parallel as signal verification. The study also revealed that the variability of operating conditions is large and thus in the vibration signal, its frequency contents and amplitudes of characteristic components are time varying too. In a typical planetary gear train, the rotary motion of the planet carrier is driven by meshing among the planet, sun gear and ring gear. Therefore, its torsional vibration characteristics are mainly related to the meshing frequency among the gears (Zhang et al. (2018). The vibration model of four-stage helicopter transmission system was proposed by Chen et al. (2017) using lumped mass method, and the result revealed that the system input shaft and the sun gear input shaft are the key shafts of the system due to their torsional stiffness affecting the low frequency region much more than other shafts. Moreover, the system input shaft and sun gear shaft had greater influence on 1st natural frequency of the system. Vicuña (2012) studied the influence on vibrations of the external gear meshing processes and the transmission path of vibrations from their source to the sensor through sun gear and carrier plate. It was observed that the external meshing processes can affect all spectral components of the total vibrations differently, depending on if the number of teeth of the planet gears are even or odd. Moreover, the transmission path through the sun gear and carrier plate affected only the spectral components at the gear mesh frequency and its harmonics. Etuk and Ikpe (2020) evaluated the deflections undergone by four carbon steel materials applicable to statically loaded sun gear shaft in 2-stage planetary gear train to determine the static nodal stresses, static displacement and static strain. The analysis was carried out on the following materials: AISI 1020 Steel (cold rolled), cast carbon steel, cast carbon steel (cold rolled), AISI 4130 steel (annealed at $865 \mathrm{oC}$ ); and Factor of Safety (FOS) of $13,8.9,9.1$ and 15 was obtained while the strength possessed by each material before failure were 
observed as: $3.22 \mathrm{e}+08,2.21 \mathrm{e}+08,2.56 \mathrm{e}+08$ and $4.31 \mathrm{e}+08 \mathrm{MPa}$. The result revealed that a higher Factor of Safety (FOS) can minimize the failure rate while improving the strength possessed by the shaft material before failure. The von-Mises stress, resultant displacement and equivalent strain values obtained were within the permissible limit. Gorshkova and Nekrasov (2019) proposed a design and kinematics scheme of a non-coaxial multiple-speed shaftplanetary gearbox, type 24R10. The non-coaxial shaftplanetary gearbox contained two shafts, on which two rows of reverse gears and three pairs of direct gears are freely installed, and a simple three-link PM consisting of a carrier with satellites that are engaged with the sun gear and epicyclic wheel. It also consist of six striker clutches to provide the planetary gear with four modes: slow, delaying, direct and accelerating. It was concluded that the propose design can lead to improvement in the layout and performance characteristics of the gearbox and, accordingly, the operational capabilities of transmission of transport vehicles, tractor trains, construction and road vehicles, tractors, ground-based special-purpose vehicles. Chen et al. (2018) considered a time-varying meshing stiffness and torsional stiffness of gear shaft in a vibration model of four-stage main helicopter transmission system established through the lumped mass method. The system input shaft $\left(k_{\text {in }}\right)$ and sun gear shaft $\left(k_{6 \mathrm{~s}}\right)$ were the key shafts of the system, and the system was observed to be in the low frequency region when their torsional stiffness is low and tends to have resonance. The findings revealed that for the first order natural frequency, torsional stiffness of two key shafts must not be too low at the same time in order to avoid resonance frequency. Torsional stiffness of the sun gear shaft $\left(k_{6 \mathrm{~s}}\right)$ was dominant for natural frequency of the fifth order and neither torsional stiffness of the two key shafts affected the system's stability when the operating frequency was lower than $1100 \mathrm{~Hz}$. Patil et al. (2017) reported that when the gears are compact with no geometrical errors or interference, rotational motion will be transmitted perfectly due to less friction between the meshing gear teeth. This may likely result in less vibration, thereby, transmitting a constant torque from the input shaft to the output shaft while allowing a constant speed from the input shaft to the output shaft. On the other hand, when the gears are not compact, it is likely to operate with geometrical errors or interference, vibration (due to high natural frequencies) and sound (noise). This may result in the rotational motion of the gear being transmitted imperfectly due to the presence of vibration, wear, deflection and friction between the meshing gear teeth (Cooley and Parker, 2014; Etuk et al., 2019). This may also subject the gear shaft to loading conditions such as torsion, bending, and sometimes axial loading, thereby, affecting the transmission of power or torque and hampering the longevity and in-service performance of the gear (Loewenthal, 1984; Childs, 2014). This problem in a planetary gear train can be minimised by ensuring that two parts of the planet gear are angularly aligned for proper assembly. One of the methods of achieving this is by aligning the axes of one tooth of each part of the compound planet gear, which makes its fabrication more complicated. Assembly of such gear drives require certain angular positioning of the planet gears (Kapelevich, 2014). In this study, the frequency response of input shaft/carrier in 3-stage planetary gear train under the influence of vibration was modelled and simulated in order to compute the excitation frequency resulting from each mode shape.

\section{MATERIALS AND METHOD}

SOLIDWORKS is a solid modelling Computer Aided Design (CAD) as well as Computer Aided Engineering (CAE) tool that runs mainly on Microsoft Windows. Modelling procedure of the input shaft/carrier in this study started with 2D sketch, consisting of geometries such as arcs, points, conics, lines, splines and so on. Dimensions were added to the sketch to define the size and configuration of the geometry. Relations in the tool bar were used to define features such as parallelism, tangency, concentricity, perpendicularity among others. In the part assembly, sketches of individual parts were assembled together to form the intended solid model of the machine. Views were automatically generated from the solid model; and dimensions and tolerances were added to the drawing as required. In recent times, SOLIDWORKS software have been successfully employed as a major tool in the modelling and simulation of engineering components such as design of remotely controlled hydraulic Bottle Jack (Ikpe and Owunna, 2019), design of a Modular Melon depodding machine (Ogiemudia et al. 2020), modelling and simulation of reciprocating piston (Ikpe and Owunna, 2020), 3D modelling of the in-cylinder combustion dynamics of two stroke internal combustion engine (Ikpe and Owunna, 2020) etc. The Computer Aided Design (CAD) drawings of the input shaft/carrier configuration are presented in Fig 1a-c.

The planet and sun gear meshes in order to allow their pitch circles roll without slip. Amidst this process, there is also an interplay between the planets, the ring gear (which is fixed to the inertial frame) and the sun gear which is driven by a cetral shaft (input shaft/carrier). In otherwords, the planet gears are held to the carrier which is fixed to the planets in the orbit relative to each other. 


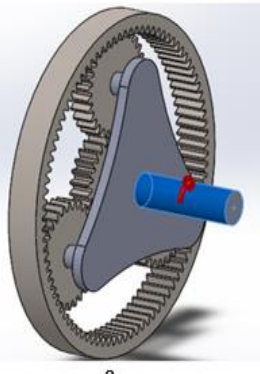

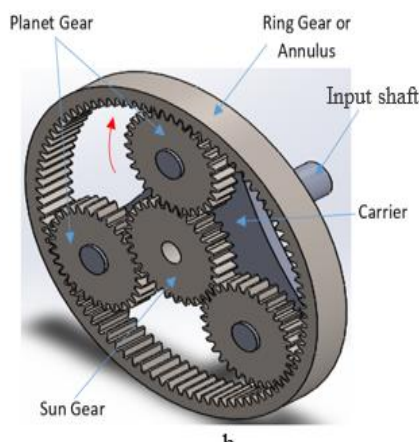

Fig. 1c. Input shaft/carrier configuration

Table 1. Properties of the input shaft material

\begin{tabular}{lll}
\hline Model Reference & \multicolumn{1}{c}{ Material Properties } \\
\hline & Name & AISI 4130 Steel (annealed at $865^{\circ} \mathrm{C}$ ) \\
& Model type & Linear Elastic Isotropic \\
& Default failure criterion & Max von Mises Stress \\
& Yield strength & $4.6 \mathrm{e}+08 \mathrm{~N} / \mathrm{m}^{\wedge} 2$ \\
& Tensile strength & $5.6 \mathrm{e}+08 \mathrm{~N} / \mathrm{m}^{\wedge} 2$ \\
& Mass density & $7850 \mathrm{~kg} / \mathrm{m}^{\wedge} 3$ \\
& Elastic modulus & $2.05 \mathrm{e}+11 \mathrm{~N} / \mathrm{m}^{\wedge} 2$ \\
& Poisson's ratio & 0.285 \\
& Shear modulus & $8 \mathrm{e}+10 \mathrm{~N} / \mathrm{m}^{\wedge} 2$
\end{tabular}

Table 2. Loads and Fixtures on the input shaft/carrier model

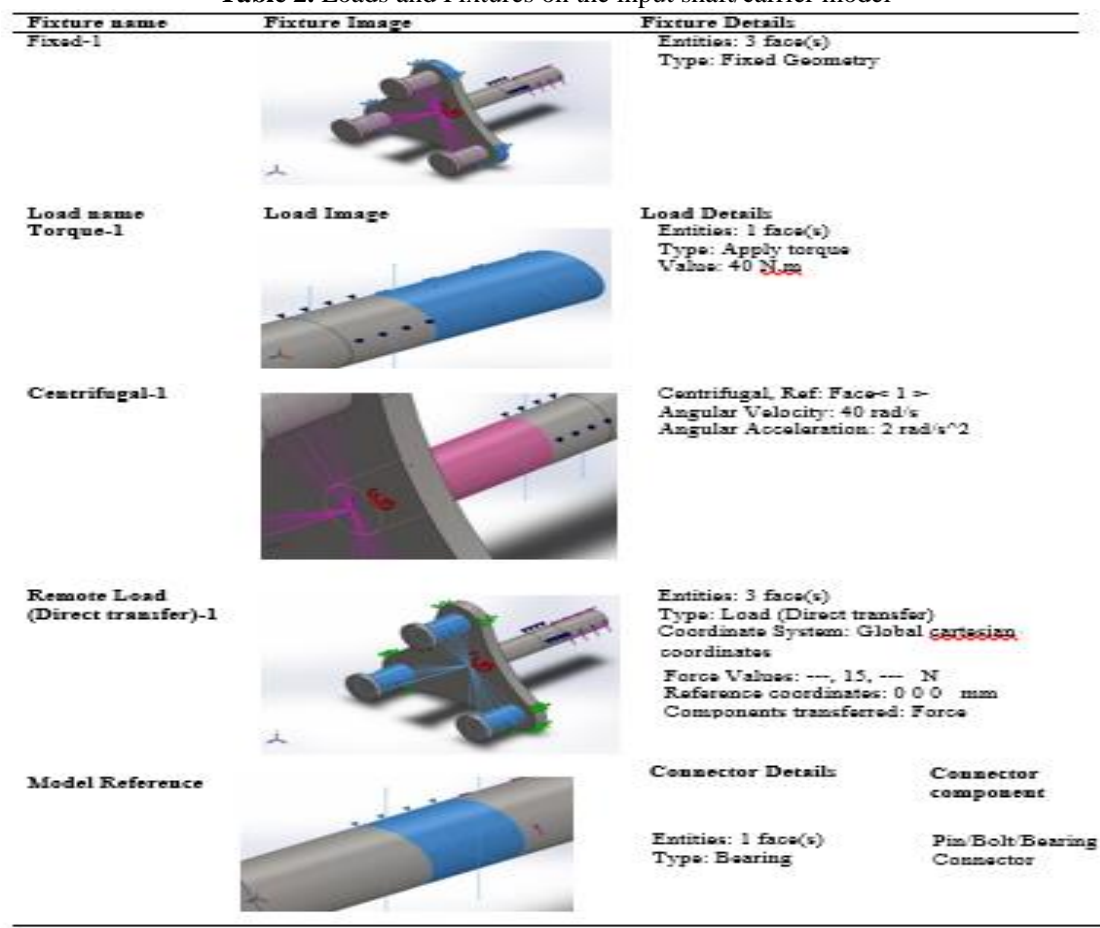

Table 3. Mesh settings and study properties of the model

\begin{tabular}{ll}
\hline Mesh Settings & Study Properties \\
\hline Mesh type: Solid Mesh & Analysis type: Frequency \\
Mesher Used: Blended curvature-based mesh & Mesh type: Solid Mesh \\
Jacobian points: 4 Points & Number of frequencies: 5 \\
Maximum element size: $9.86644 \mathrm{~mm}$ & Solver type: Direct sparse solver \\
Minimum element size: $9.86644 \mathrm{~mm}$ & Zero strain temperature: 298 Kelvin \\
Mesh Quality Plot: High & Thermal option: Include temperature loads \\
\hline
\end{tabular}

ETUK, EM; EBHOJIAYE, RS; EKANEM, KR 
The ring gear, meshes with each of the planet gears, the carrier holds the planet and sun gears in position for accurate rotation and transmission of motion as shown in the planetary gear configurations in Fig 1ab.

Solidworks SimulationXpress was employed in this study to analyse the frequency of input shaft/carrier in planetary gear train. The platform in SimulationXpress employs elements of the full simulation interface to navigate through a step-by-step sequence of specifying fixtures, loads, material selection, analizing and simulating the model and viewing of results. On completion of a step, the information is saved automatically to the SimulationXpress study tree for easy access. The validity of results obtain depends upon the condion that, specified material properties accurately represent the part materials while the fixtures and loads accurately represent the part working conditions. The simulation process is stated as follows:

i. Option: Sets default simulation units and specifies a folder for saving simulation results.

ii. Fixtures: Applies fixtures to faces of the body.

iii. Loads: Applies forces, pressures or both to the faces of the body.

iv. Material: Assigns material properties to the part.

v. Run: Uses the default settings or changed settings for the simulation.

vi. Results: Shows resultant displacement distribution on the model with or without annotation for the maximum and minimum deformation. It also shows deformed shape of the model.

\begin{tabular}{ll} 
Table 4. Mesh information of the input shaft/carrier model \\
\hline Mesh information & Values \\
\hline Total Nodes & 20933 \\
Total Elements & 12681 \\
Maximum Aspect Ratio & 5.4865 \\
$\%$ of elements with Aspect Ratio < 3 & 99.9 \\
$\%$ of elements with Aspect Ratio > 10 & 0 \\
$\%$ of distorted elements(Jacobian) & 0 \\
Time to complete mesh (hh;mm;ss) & $00: 00: 13$ \\
\hline
\end{tabular}

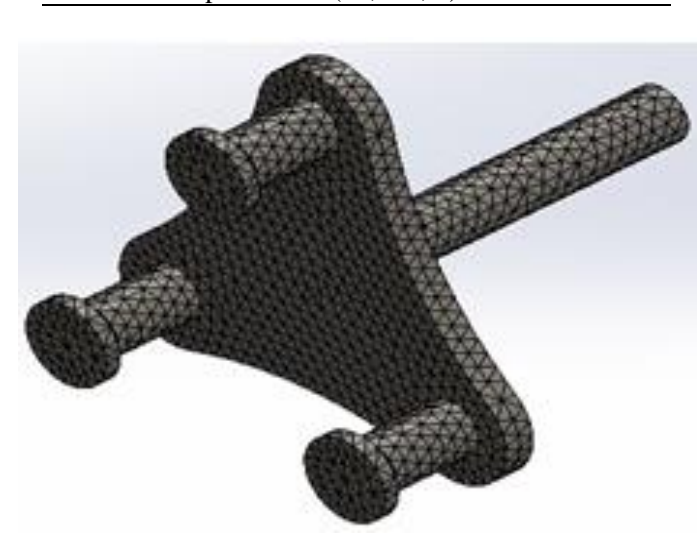

Fig. 2. Mesh visualization of the input shaft/carrier
Properties of the input shaft material are presented in Table 1, loads and fixtures on the input shaft/carrier model are presented in Table 2, mesh settings and study properties of the model are shown in Table 3 and mesh information of the input shaft/carrier model is represented in Table 4 with the mesh visualization shown in Fig 2.

\section{RESULTS AND DISCUSSION}

The vibrating planetary gear as it undergoes rotary motion translates the vibrating effect to the input shaft/carrier and other parts of the gear. This relates to the frequency/amplitude on the input shaft resulting from vibration of the planetary gear train during each rotation cycle. In this context, amplitude is the maximum displacement or distance moved by a point on the vibrating input shaft/carrier or wave measured from its equilibrium position. Considering these waves generated by the vibrating input shaft, their amplitude is proportional to the amplitude of the shaft. The amplitude of these waves usually decreases from the peak point, and diminishes as its energy is being lost, and is referred to as damped. The vibration effects translated from the gear train to the input shaft is characterised by periodic back-and-forth motion of the shaft, oftentimes resulting when the input shaft is displaced from its equilibrium condition and allowed to respond to the forces that tend to restore it back to its equilibrium state. Vibrations ensue when a body is subject to any arrangement of forces (Owunna et al., 2016). Vibration effects transferred from planetary gear train to the input shaft is classified under two categories namely: free and forced vibration. Free vibration in this case occurs when the rotary motion of the input shaft due to radial forces is disturbed momentarily and then allows to proceed without restrain. In other words, as the input shaft is disturbed from its uniform rotary motion, it tends to vibrate at certain frequencies known as natural or resonant frequencies which is the frequency is the frequency at which a body vibrates when excited by a force (EfeOnoneme et al., 2018). The rotary motion is characterised by a change in the orientation of the body with respect to time, and generally has the same velocity (directed speed) and acceleration (time rate of change of velocity). Forced vibration which is also applicable in this case occurs when the input shaft is continuously driven by an external components, during which the input shaft under goes simple harmonic motion (SHM) and driven by sinusoidal forces. This may leads to resonance which occurs when the driving frequency approaches the natural frequency of free vibrations. The resonance is therefore the excessive response that occurs when the input shaft is subjected to a dynamic load vibrating at one of its natural frequencies (Etuk et al., 2021). This 
frequency represent the number of waves that pass a fixed point in unit time or the number of cycles or vibration that occurs on the input shaft during one unit of time in a periodic motion. For each natural frequency, the input shaft takes a certain shape known as mode shape as shown on the plots generated from input shaft frequency analysis in Fig 3-7.

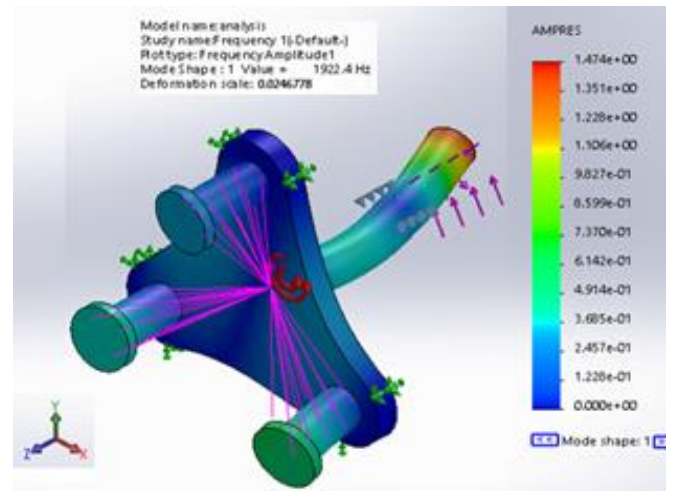

Fig. 3. Natural frequency and associated mode shape 1

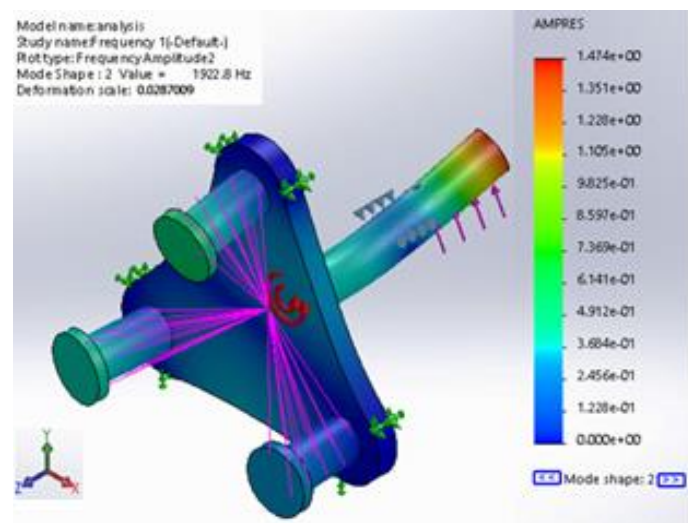

Fig. 4. Natural frequency and associated mode shape 2

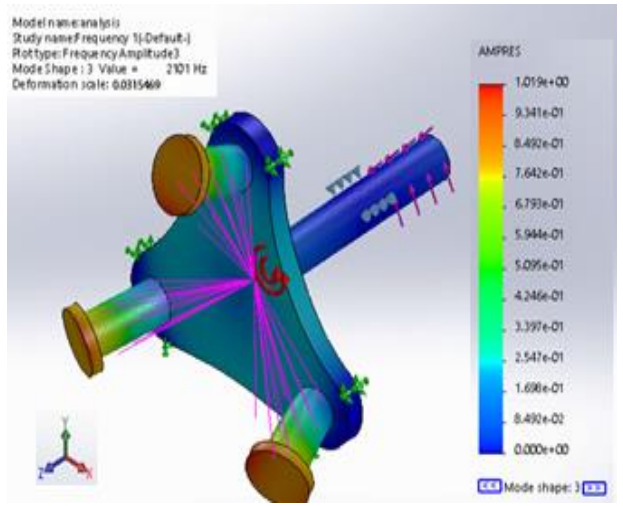

Fig. 5. Natural frequency and associated mode shape 3

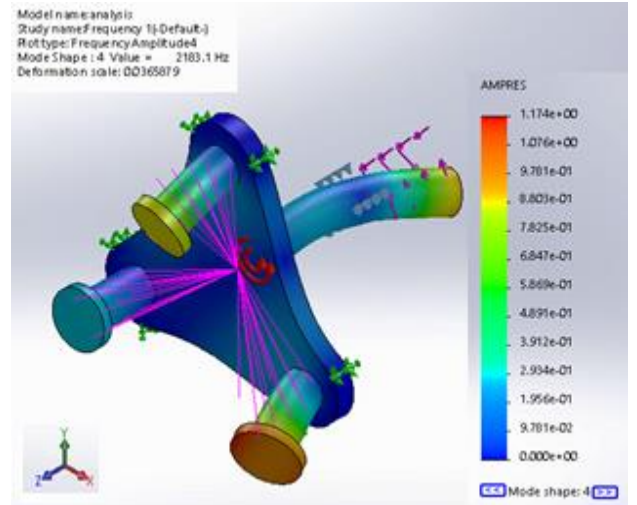

Fig. 6. Natural frequency and associated mode shape 4

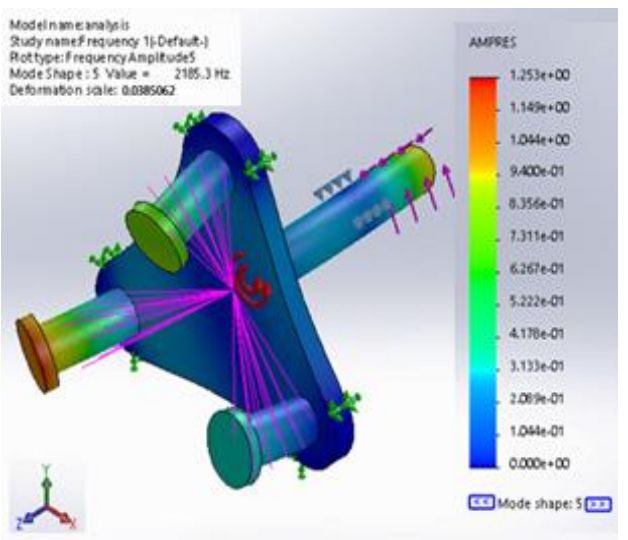

Fig. 7. Natural frequency and associated mode shape 5

Results obtain from the input shaft frequency analysis in Fig 3-7 shows deformation scale values of $0.0246778,0.0287009,0.0315469,0.0365879$ and 0.0385062 for mode shape $1-5$. The deformation scale is the scaling factor used by SimulationXpress to scale the deformed shape of the input shaft model. The value of the scale factor depends on the model's largest dimension and the computed deformations. A larger deformation scale enables the user visualize deformations that are a lot smaller compared to the original dimensions of the model. Deformation scale factor also known as amplitude modulation plays a vital role in scaling the maximum displacement amplitude for visualizing a deformed shape of an image. In other words, the use can either choose a large scaling factor to zoom on the deformed geometry or a small coefficient to obtain a realistic visualization. Figure 8 represents a plot of mode shapes against deformation scale. The frequency analysis calculates the natural frequencies on the input shaft and their associated mode shapes as well as deformation scale which is a scale factor that SimulationXpress uses to scale the deformed shape of the model. As shown in Fig 3-7, results obtain from the input shaft/carrier frequency analysis shows natural frequency values of $1922.4 \mathrm{~Hz}, 1922.8 \mathrm{~Hz}, 2101 \mathrm{~Hz}, 2183.1 \mathrm{~Hz}$ and 2185 . 
$3 \mathrm{~Hz}$ for mode shape 1-5. Natural frequency $(\mathrm{Hz})$ on the input shaft against mode number is graphically represented in Fig 9. The graphical presentation indicates proximity in the frequency values obtained for mode shape 1 and 2 . However, there appears to be a large disparity in terms of increase in the frequency values obtained for mode shape 3 and 4, while there was closeness in the frequency values obtained for mode shape 4 and 5. Table 5 represents summary of frequency values at different mode shapes while its graphical representation in Fig 9 indicates that natural frequency of the input shaft increases gradually as the mode no increase.

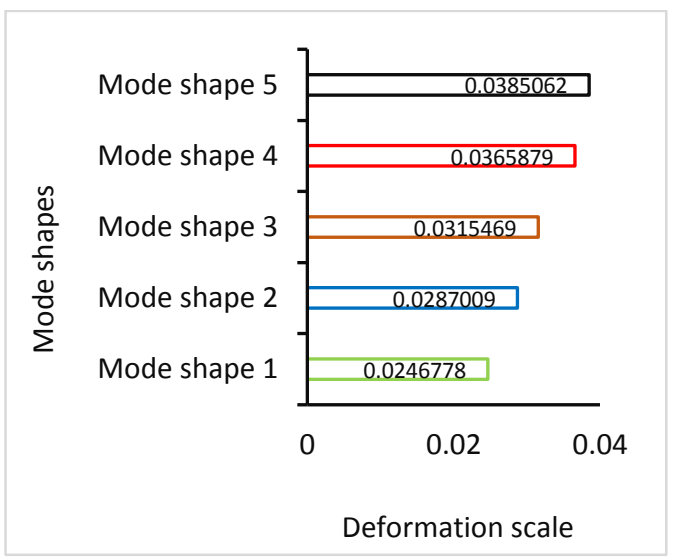

Fig. 8. Plot of mode shapes against deformation scale

Table 5. Summary of frequency values at different mode shapes

\begin{tabular}{llll}
\hline Mode shapes & Rad/sec & Hertz & Seconds \\
\hline 1 & 12079 & 1922.4 & 0.00052017 \\
2 & 12082 & 1922.8 & 0.00052006 \\
3 & 13201 & 2101 & 0.00047596 \\
4 & 13717 & 2183.1 & 0.00045807 \\
5 & 13731 & 2185.3 & 0.0004576 \\
\hline
\end{tabular}

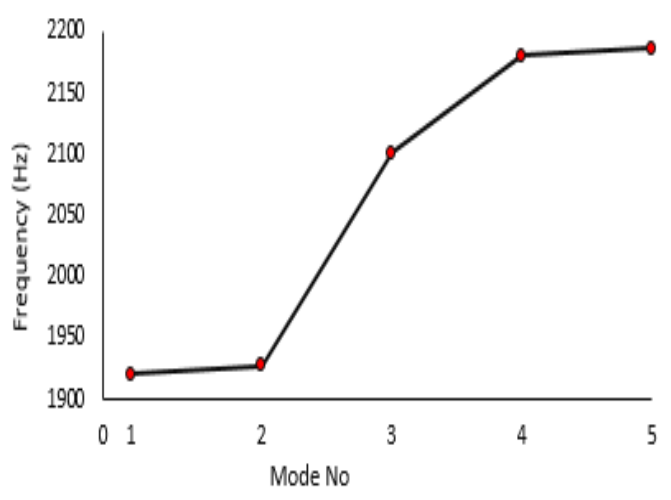

Fig. 9. Plot of frequency against mode no

Figure 10 represents plot of Cumulative Effective Mass Participation Factor (CEMPF) against frequency. The CEMPF is a measure of how the Effective Mass Participation Factor (EMPF) builds up as additional modes are included in the analysis. Therefore, the number of modes considered must contribute to a CEMPF of at least $80 \%$ of the system mass in the direction of excitation $(\mathrm{X}, \mathrm{Y}$ and $\mathrm{Z}$ direction).

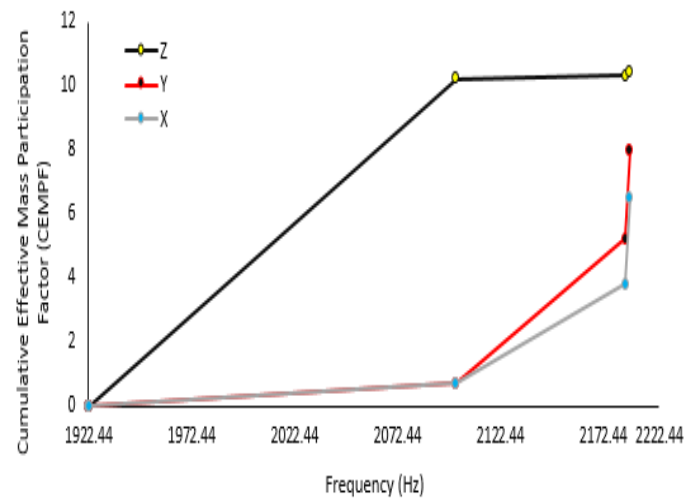

Fig. 10. Plot of Cumulative effective mass participation factor against frequency

The Effective Mass Participation Factor (EMPF) represents the percentage of the system mass that participates in a particular mode. It provides a measure of the energy contained in each resonant mode. Therefore, a mode with a large EMPF is oftentimes a significant contributor to the dynamic response of the system. The EMPF output response for the five mode shapes in $\mathrm{X}, \mathrm{Y}$ and $\mathrm{Z}$ directions are presented in Table 6 and graphically shown in Fig 11.

Table 6. EMPF output response for mode shapes in $\mathrm{X}, \mathrm{Y}$ and $\mathrm{Z}$

\begin{tabular}{lllll}
\hline $\begin{array}{l}\text { Mode } \\
\text { shape }\end{array}$ & $\begin{array}{l}\text { Frequency } \\
\text { (Hertz) }\end{array}$ & X direction & Y direction & $\begin{array}{l}\text { Z } \\
\text { direction }\end{array}$ \\
\hline 1 & 1922.4 & 0.0021263 & 0.00021127 & $\begin{array}{l}1.2128 \mathrm{e}- \\
06\end{array}$ \\
& & & & 06 \\
2 & 1922.8 & 0.00017147 & 0.0021548 & $\begin{array}{l}1.7444 \mathrm{e}- \\
06\end{array}$ \\
& & & & 0.10515 \\
3 & 2101 & $3.0205 \mathrm{e}-05$ & $2.3721 \mathrm{e}-06$ & $0.0077 \mathrm{e}-$ \\
4 & 2183.1 & 0.033195 & 0.045597 & 1.007 \\
& & & 0.032971 & $5.3709 \mathrm{e}-$ \\
5 & 2185.3 & 0.045071 & & 05 \\
& & & & \\
& & Sum X $=$ & Sum Y $=$ & Sum Z $=$ \\
& & 0.080594 & 0.080937 & 0.10522 \\
\hline
\end{tabular}

As shown in Fig 11, The EMPF output response for mode shape one indicates that the excitation motion of the input shaft is all in the global $\mathrm{X}$ direction. Therefore, zero EMPF output response is observed in the $\mathrm{Y}$ and $\mathrm{Z}$ directions, with relatively small number for EMPF in the $X$ direction. In this case, $0.212 \%$ of the system mass is participating in this mode shape in the $\mathrm{X}$ direction. From the computations by the solver, it is important to note that the calculations are based on 
the Effective Mass of the system, and not the true mass.

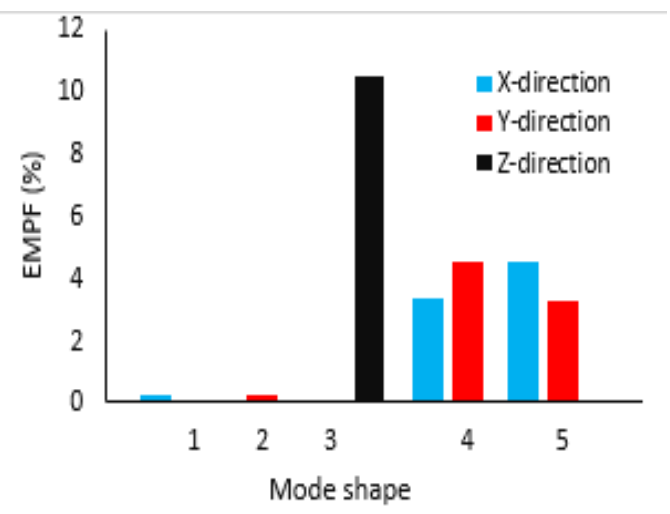

Fig. 11. Plot of EMPF against the input shaft/carrier mode shapes

The EMPF output response for mode shape two is different from that obtained from mode shape one, as excitation motion of the input shaft is all in the global $\mathrm{Y}$ direction. However, zero EMPF output response is observed in the $\mathrm{X}$ and $\mathrm{Z}$ directions, with relatively small number for EMPF in the Y direction. In this case, $0.215 \%$ of the system mass is participating in this mode shape in the $\mathrm{X}$ direction. The EMPF output response for mode shape three is different from that obtained from mode shape one and two, as excitation motion of the input shaft is all in the global $\mathrm{Z}$ direction. However, zero EMPF output response is observed in the $\mathrm{X}$ and $\mathrm{Y}$ directions, with a large number for EMPF in the $\mathrm{Z}$ direction. In this case, $10.5 \%$ of the system mass is participating in this mode shape in the $Z$ direction. For mode shape four, the excitation motion of the input shaft is all in the global $\mathrm{X}$ and $\mathrm{Y}$ directions. However, zero EMPF output response is observed in the $\mathrm{Z}$ direction, with a reasonable number for EMPF in the $\mathrm{X}$ and $\mathrm{Y}$ directions. In this case, $3.31 \%$ and $4.55 \%$ of the system mass is participating in this mode shape in the $\mathrm{X}$ and $\mathrm{Y}$ directions. Finally for mode shape five, excitation motion of the input shaft is in the global $\mathrm{X}$ and $\mathrm{Y}$ directions as is the case in mode shape four. However, zero EMPF output response is observed in the $\mathrm{Z}$ direction, with a reasonable number for EMPF in the $\mathrm{X}$ and $\mathrm{Y}$ directions. In this case, $4.50 \%$ and $3.29 \%$ of the system mass is participating in this mode shape in the $\mathrm{X}$ and $\mathrm{Y}$ directions. In cases where the EMPF in the $\mathrm{X}, \mathrm{Y}$ and $\mathrm{Z}$ directions of a particular mode are zero, it implies that the mode is symmetric, and the centre of gravity experiences no movement in the direction of symmetry. Therefore, as a percentage of Effective mass participating in that mode, the solution will indicate zero. This is because the EMPF obtained for a particular mode and each direction is a reflection of how the centre of gravity of the structure gets excited by that mode (Finkelstein, 2019).
Conclusion: In this study, the vibration behaviour of the input shaft was analysed by computing the natural frequencies and mode shapes. While the natural frequency associated with each vibration cycle increased gradually with each of the mode number, mode shapes associated with each vibration cycle and mode number was characterised by distinct deformation shapes. This indicated that, high rate of natural frequencies are likely caused by increasing rate of excitations, leading to intensed deformation on the mode shapes.

\section{REFERENCES}

Moshrefzadeh, A; Fasana, A (2017). Planetary gearbox with localised bearings and gears faults: simulation and time/frequency analysis. Meccanica. 1: 1-22.

Zimroz, R; Urbanek, J; Barszcz, T; Bartelmus, W; Millioz, F; Martin, N (2011). Measurement of Instantaneous Shaft Speed by Advanced Vibration Signal Processing-Application to Wind Turbine Gearbox. Metrology and Measurement Sys. 4: 701-712.

Owunna, I; Ikpe, AE; Satope, P; Ikpe, EE (2016). Experimental Modal Analysis of a Flat Plate Subjected To Vibration. Amer. J. Eng. Res. 5(6): 30-37.

Zhang, H; Qi, C; Jizhuang, F; Dai, F; You, B (2018). Vibration Characteristics Analysis of Planetary Gears with a Multi-Clearance Coupling in Space Mechanism. Energies. 11(2687): 1-17.

Efe-Ononeme, OE; Ikpe, AE; Ariavie, GO (2018). Modal Analysis of Conventional Gas Turbine Blade Materials (Udimet 500 and In738) for Industrial Applications. J. Eng. Tech. Appl. Sci. 3(2): 119-133.

Chen, Y; Zhu, R; Xiong, Y; Jin, G (2017). Analysis on natural characteristics of four-stage main transmission system in three-engine helicopter. Vibro-eng. Procedia. 12: 19-23.

Finkelstein, A (2019). Understanding Mass Participation Factor Results in Frequency Studies, Computer Aided Technology. Buffalo Grove, IL 60089, USA.

Vicuña, CM (2012). Theoretical frequency analysis of vibrations from planetary gearboxes. Forsch Ingenieurwes. 76: 15-31. 
Etuk, EM; Ikpe, AE (2020). Resultant Deflections from Static Analysis of Sun Gear Rotor Shaft Materials to Determine their Performance in 2Stage Planetary Gear Operations. Int. J. Eng. Sci. Appl. 4(2): 73-91.

Gorshkova, OO; Nekrasov, VI (2019). Non-Coaxial 24-Speed Shaft-Planetary Gearbox. Int. J. Inn. Tech. Expl. Eng. 8(12): 411-418.

Etuk, EM; Ikpe, AE; Ndon, AE (2021). Modal Analysis of Horizontal Axis Wind Turbine Rotor Blade with Distinct Configurations under Aerodynamic Loading Cycle. GU. J. Sci. Pt A: Eng. Innov. 8(1): 81-93.

Chen, Y; Zhu, RP; Xiong, YP; Jin, GH (2018). 2902. Influence of shaft torsional stiffness on natural characteristics of four-stage main transmission system in three-engine helicopter. J. Vibro-eng. 20(5): 1955-1965.

Loewenthal, SH (1984). Design of Power Transmitting Shafts. Lewis Research Centre Cleveland, Ohio, NASA Reference Publication, 1123.

Childs, P (2014). Mechanical Design Engineering Handbook. Butterworth-Heinemann, ISBN: 9780-08-097759-1.

Kapelevich, A (2014). High Gear Ratio Epicyclic Drives Analysis. Gear Tech., 2: 62-67.

Etuk, EM; Ikpe, AE; Adoh, AU (2019). Modelling and Analysis of 2-Stage Planetary Gear Train for Modular Horizontal Wind Turbine Application. $J$. Appl. Res on Indus. Eng. 6(4): 268-282.
Patil, SJ; Singh, VB; Pawar, AM (2017). Design and Vibration Analysis for Shaft with Gear Mountings using Finite Element Analysis. Int. Adv. Res. J. Sci, Eng. Tech. 4(1): 30-33.

Cooley, CG; Parker, RG (2014). A Review of Planetary and Epicyclic Gear Dynamics and Vibrations Research. Trans. ASME, Appl. Mech. Rev. 66(040804): 1-15.

Ikpe, AE; Owunna, IB (2020). Design Analysis of Reciprocating Piston for Single Cylinder Internal Combustion Engine. Int. J. Auto. Sci. Tech. 4(2): 30-39.

Ikpe, AE; Owunna, IB (2020). A 3D Modelling of the In-Cylinder Combustion Dynamics of Two Stroke Internal Combustion Engine in its Service Condition. Nig. J. of Tech. 39(1): 161-172.

Ikpe, AE; Owunna, IB (2019). Design of Remotely Controlled Hydraulic Bottle Jack for Automobile Applications. Int. J. Eng. Res. Dev. 11(1): 124134.

Ogiemudia, OG; Ikpe, AE; Chughiefe, LE (2020). Design and Fabrication of a Modular Melon Depodding Machine for Optimum Performance in Nigerian Agricultural Sector. Euro. Mech. Sci. 4(3): 103-112. 